\title{
The effect of caffeine ingestion in prevention of post-operative ileus after caesarean section: a randomized controlled trial
}

\author{
Amr A. Nadim¹, Reda M. Ghanem', Madonna G. Benyamine', Fady N. Abdallah², \\ Ahmed M. Abbas* ${ }^{2 *}$
}

\begin{abstract}
${ }^{1}$ Department of Obstetrics and Gynecology, Faculty of Medicine, Ain Shams University, Cairo, Egypt
${ }^{2}$ Department of Obstetrics and Gynecology. Faculty of Medicine, Assiut University, Assiut, Egypt
\end{abstract}

Received: 30 September 2019

Accepted: 31 October 2019

\section{*Correspondence:}

Dr. Ahmed M. Abbas,

E-mail: bmr90@hotmail.com

Copyright: (c) the author(s), publisher and licensee Medip Academy. This is an open-access article distributed under the terms of the Creative Commons Attribution Non-Commercial License, which permits unrestricted non-commercial use, distribution, and reproduction in any medium, provided the original work is properly cited.

\begin{abstract}
Background: Caesarian section (CS) has become more prevalent than the vaginal delivery in Egypt. Many complications could occur after an abdominal surgery. One of the commonest but yet serious complications is the postoperative ileus that can possibly be prevented by caffeine ingestion. The aim of the study is to assess the value of caffeine ingestion in promoting intestinal motility and prevention of postoperative ileus after CS.

Methods: This is a randomized controlled trial that was conducted on 560 cases who were recruited from emergency unit and inpatient wards in Ain Shams University maternity hospital. The patients were divided into two groups where the intervention group received caffeinated coffee while the other group received decaffeinated coffee.

Results: There was statistically significant difference between the two groups regarding the bowel function after CS ( $\mathrm{p}$ <0.05). The intervention group had improved intestinal functions after the CS. Patients from the intervention group had audible intestinal sound sooner than the control group. In addition, they passed flatus and were able to tolerate food in less time.

Conclusions: Consuming caffeinated coffee after CS contributes significantly to faster restoration of intestinal function. Coffee is a popular drink and can be used to decrease the incidence of postoperative ileus-related complications.
\end{abstract}

Keywords: Caffeine, Cesarean section, Intestinal motility, Postoperative ileus

\section{INTRODUCTION}

Caesarian section (CS) has become more prevalent than the vaginal delivery in Egypt. According to the Demographic and Health Survey (DHS) in 2014, 52\% of women in Egypt give birth by CS. This makes CS one of the commonest abdominal surgeries in Egypt. Many complications could occur after an abdominal surgery. One of the commonest but yet serious is the postoperative ileus. ${ }^{1}$ Postoperative ileus complicates $10-15 \%$ of CS. $^{2}$
Postoperative ileus is a predictable delay in gastrointestinal motility that occurs after abdominal surgery. Probable causes include disruption of the sympathetic/parasympathetic pathways to the gastrointestinal tract, inflammatory changes through multiple pathways, and the use of opioids for the management of postoperative pain. Postoperative ileus is presented with nausea, vomiting, abdominal distention, abdominal tenderness, and delayed passage of flatus and stool. These symptoms would remarkably worsen the 
patients' quality of life, increase length of hospital stay, and increase costs associated with postoperative recovery. ${ }^{3}$

Although ileus is so prevalent, preventative therapeutic options are still limited. Many trials have been made to prevent ileus, including administration of prokinetic drugs such as serotonin receptor antagonists, neostigmine, alvimopam, and ghrelin agonists. ${ }^{4-7}$ Other studies tried early resumption of feeding, gum chewing and adequate pain control as a prophylactic method against postoperative ileus. ${ }^{8-10}$ Unfortunately, none of these strategies has been completely successful.

Coffee is one the most popular drinks in Egypt and the whole world. Several researches were done worldwide to study the effect of the caffeine present in coffee and resumption of intestinal motility after various abdominal surgeries. ${ }^{11,12}$ Recently the effect of coffee on prevention of postoperative ileus after caesarean section was researched. ${ }^{13}$ That's why this study is designed to determine the efficacy of the caffeine present in coffee in prevention of postoperative ileus.

\section{METHODS}

A randomized controlled trial conducted in Ain Shams Maternity Hospital. one-year study with women were recruited from emergency unit and inpatient wards in Ain Shams University maternity hospital.

\section{Inclusion criteria}

- Caesarean section

- Spinal anesthesia

- Total surgery time less than 90 minutes.

\section{Exclusion criteria}

- Previous complicated abdominal surgery or caesarean section with extensive adhesions requiring extensive dissection or intestinal manipulation

- CS complicated with postpartum hemorrhage or in the women who received misoprostol

- Intraoperative intestinal complications

- Intraoperative respiratory complication

- Chronic intestinal diseases: irritable or inflammatory bowel diseases

- Chronic diarrhea or constipation

- Using laxatives pre-operatively

- Known hypersensitivity to caffeine

- Thyroid or hepatic disease

- Cardiac arrhythmias.

\section{The primary outcome}

- The number of hours for women to first pass flatus after CS.

\section{Secondary outcomes}

- The number of hours for the women to have their first intestinal sound to be heard by a stethoscope

- The number of hours for the women to pass stool

- The duration of women's hospital stays

- The incidence of postoperative spinal headache.

\section{Randomization method}

A statistician, not otherwise engaged in the study, prepared a computer-generated random table and placed the allocation data in serially numbered sealed opaque envelopes. All recruited women were distributed into two groups according to a computerized randomization table. The researcher consecutively opened the envelopes containing cards with letters either letter $(\mathrm{C})$ or letter $(\mathrm{N})$, Cards with letter $(\mathrm{C})$ represented the group that received the caffeinated coffee and cards with letter (N) represented the group that received the decaffeinated coffee. Once the allocation has been done, it could not be changed.

\section{Sample size}

The number of samples was calculated according to a study by Müller et al, considering the power of $90 \%$, confidence $95 \%$ and significant level of 0.05 , the sample size needed was 544 cases, and with adding $10 \%$ for occasional cases' drop out so the total sample size was 600 cases. We managed to recruit 560 cases distributed into two groups, 275 received the caffeinated coffee $(C)$ group and the 285 received the decaffeinated coffee $(\mathrm{N})$ group.

\section{Study design}

This study included 560 women undergoing CS. The study aims were explained to all women and an informed written consent was taken.

\section{Procedure}

- For all women, the anesthetic used was Marcaine ${ }^{\circledR}$ Spinal heavy $0.5 \%$ and fentanyl and for postoperative pain, ketorolac was used

- Through Pfannenstiel incision, transverse lower segment uterine incision was done, with the duration of the surgery not exceeding 60 minutes

- Women were not permitted to drink or eat, except for the drink offered by the researcher, till passing flatus. Early ambulation was encouraged. Each cup of coffee was containing $100 \mathrm{ml}$ and taken under supervision of the researcher. The sup of coffee was administered every 4 hours post-operative

- A stethoscope was used to detect the first intestinal movement each hour after the surgery. The women were advised to notify the researcher when they passed both flatus and feces. 


\section{Statistical analysis}

Data coding and data entry were done using the statistical package SPSS (Statistical Package for the Social Sciences) version 22 (SPSS software Chicago, IL, USA). Data were summarized as mean and standard deviation for quantitative data and as frequency and percentage for categorical data. Comparisons between quantitative variables were made using Kruskal-Wallis and MannWhitney tests if the variables are not-normally distributed. Student's t-test was used for normally distributed data. For comparing categorical data, Chisquare (X2) test was performed. P-values less than 0.05 were considered as statistically significant.

\section{RESULTS}

Regarding the demographic and baseline clinical characteristics of the study groups, there were no significant differences between groups regarding age, BMI, gestational age, number of previous pregnancy and number of previous delivery (Figure 1,2).

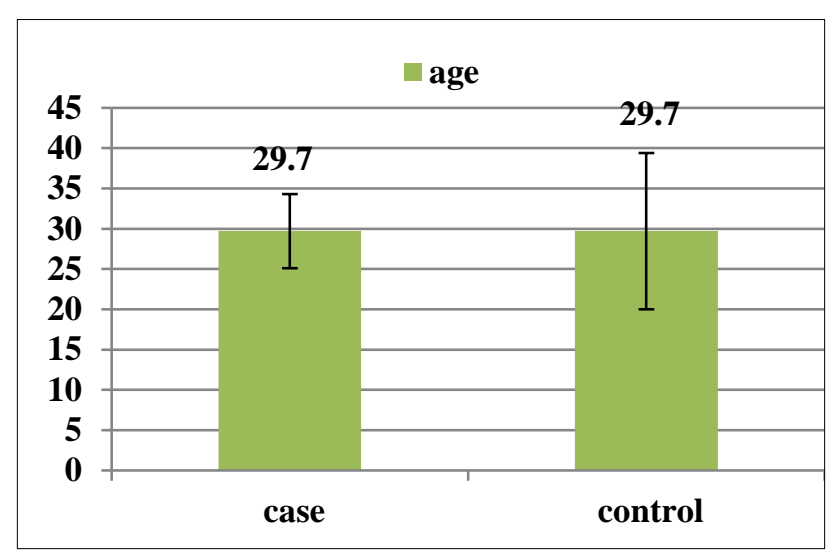

Figure 1: Mean age between studied groups.

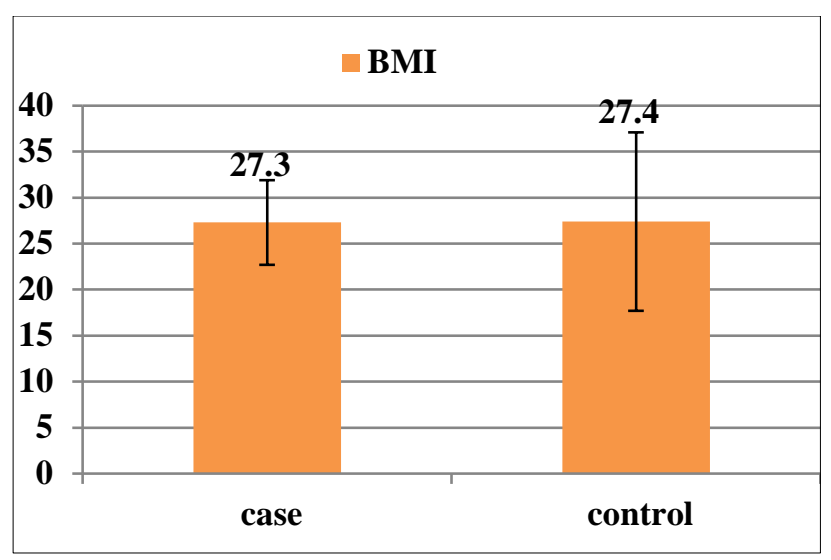

Figure 2: Mean BMI between studied groups.

Table 1: Causes of CS among studied patients.

\begin{tabular}{|lllll|} 
& $\begin{array}{l}\text { Intervention } \\
(\mathrm{n}=275) \\
(\mathbf{1 0 0 \%})\end{array}$ & $\begin{array}{l}\text { Controls } \\
(\mathrm{n}=285) \\
(\mathbf{1 0 0 \%})\end{array}$ & $\chi 2$ & $\begin{array}{l}\mathrm{P} \\
\text { value }\end{array}$ \\
\cline { 1 - 3 } $\begin{array}{l}\text { Emergent } \\
\text { cause }\end{array}$ & $70(25.4)$ & $55(19.3)$ & & \\
\cline { 1 - 3 } $\begin{array}{l}\text { Elective } \\
\text { cause }\end{array}$ & $205(74.5)$ & $230(80.7)$ & 0.587 \\
\hline
\end{tabular}

Data is shown as mean \pm standard deviation. $\chi 2$ tests were used. Bold values are statistically significant at $\mathrm{p}<0.05$.

Table 2: Operation time in the studied groups.

\begin{tabular}{|c|c|c|c|c|}
\hline & $\begin{array}{l}\text { Patients } \\
(\mathrm{n}=\mathbf{2 7 5})\end{array}$ & $\begin{array}{l}\text { Controls } \\
(n=285)\end{array}$ & t- test & $\begin{array}{l}P \\
\text { value }\end{array}$ \\
\hline \multicolumn{5}{|c|}{ Operation time in minutes } \\
\hline Mean \pm SD & $41.8 \pm 4.2$ & $42.3 \pm 4.5$ & \multirow{2}{*}{-1.559} & \multirow{2}{*}{0.06} \\
\hline Range & $35-50$ & $35-50$ & & \\
\hline
\end{tabular}

Table 3: The bowel function after CS among studied patients.

\begin{tabular}{|c|c|c|c|c|}
\hline & Patients $(n=275)$ & Controls $(\mathrm{n}=285)$ & t- test & P value \\
\hline \multicolumn{5}{|c|}{ 1-The first audible bowel sound (hours) } \\
\hline Mean \pm SD & $6.2 \pm 0.73$ & $9.9 \pm 1.2$ & \multirow{2}{*}{-45.2} & \multirow{2}{*}{$0.01 *$} \\
\hline Range & $5-10$ & $5.6-13$ & & \\
\hline \multicolumn{5}{|c|}{ 2-The first time to pass of flatus (hours) } \\
\hline Mean \pm SD & $14.9 \pm 2.1$ & $23.01 \pm 3.5$ & \multirow{2}{*}{-34.6} & \multirow{2}{*}{$0.02 *$} \\
\hline Range & $15-32$ & $12.8-28$ & & \\
\hline \multicolumn{5}{|c|}{ 3-The first time to defecate (hours) } \\
\hline Mean \pm SD & $29.9 \pm 2.9$ & $30.7 \pm 3.2$ & \multirow{2}{*}{-42.65} & \multirow{2}{*}{0.212} \\
\hline Range & $15-33$ & $16.2-37$ & & \\
\hline \multicolumn{5}{|c|}{ 4- Ability to tolerate solid food postoperatively (hours) } \\
\hline Mean \pm SD & $18.2 \pm 2.2$ & $30.2 \pm 3.3$ & \multirow{2}{*}{-52.535} & \multirow{2}{*}{$0.001 *$} \\
\hline Range & $15-32$ & $23-34$ & & \\
\hline
\end{tabular}

Data is shown as mean \pm standard deviation. Student-t tests were used. *Bold values are statistically significant at $p<0.05$. 
The current study showed that there was no significant difference between groups regarding causes of caesarean section. In the intervention group there were 205 elective caesarean sections (74.5\%) and 70 emergent CS (25.4\%). In the control group there were 230 elective caesarean sections (80.7\%) and 55 emergent CS (19.3\%) (Table 1). The mean operation duration among studied patients was $41.8 \pm 4.2$ in group $\mathrm{C}$ and $42.3 \pm 4.5$ in group $\mathrm{N}$ with no significant difference among groups (Table 2).

Intestinal performance shows significant difference between two groups in passing the first flatus which was recorded at $14.9 \pm 2.1$ hours in the intervention group while it was $23.01 \pm 3.5$ hours in the control group $(\mathrm{p}=0.02)$. It also shows that first bowel sound was audible at $6.2 \pm 0.73$ hours and $9.9 \pm 1.2$ hours for intervention and control groups, respectively $(\mathrm{p}=0.01)$ (Table 3 ).

The current study showed that there was no significant difference between groups regarding post-operative nausea and vomiting ( $\mathrm{p}>0.05)$. Postoperative nausea and vomiting were observed in both control (7.1\%) and intervention $(10.9 \%)$ and there was significant difference between groups regarding postoperative abdominal distension $(\mathrm{p}<0.05)$ (Table 4$)$.

Table 4: Post -operative complaints among studied patients.

\begin{tabular}{|c|c|c|c|c|c|}
\hline \multirow{2}{*}{\multicolumn{6}{|c|}{$\begin{array}{ll} & \text { Patients }(n=275)(100 \%)\end{array}$}} \\
\hline & & & & & \\
\hline Yes & 20 & $7.1 \%$ & 30 & $10.9 \%$ & \multirow{2}{*}{0.23} \\
\hline No & 265 & $92.9 \%$ & 24. & $89.1 \%$ & \\
\hline \multicolumn{6}{|c|}{ 2-Post-operative vomiting } \\
\hline Yes & 15 & $5.3 \%$ & 17 & $6.2 \%$ & \multirow{2}{*}{0.512} \\
\hline No & 270 & $94.7 \%$ & 25 & $93.8 \%$ & \\
\hline \multicolumn{6}{|c|}{ 3-Postoperative abdominal distension } \\
\hline Yes & 3 & $1 \%$ & 25 & $9.1 \%$ & \multirow{2}{*}{$0.001 *$} \\
\hline No & 282 & $99 \%$ & 25 & $90.9 \%$ & \\
\hline
\end{tabular}

Date is shown as mean \pm standard deviation. Student-t tests were used. Bold values are statistically significant at $\mathrm{p}<0.05$.

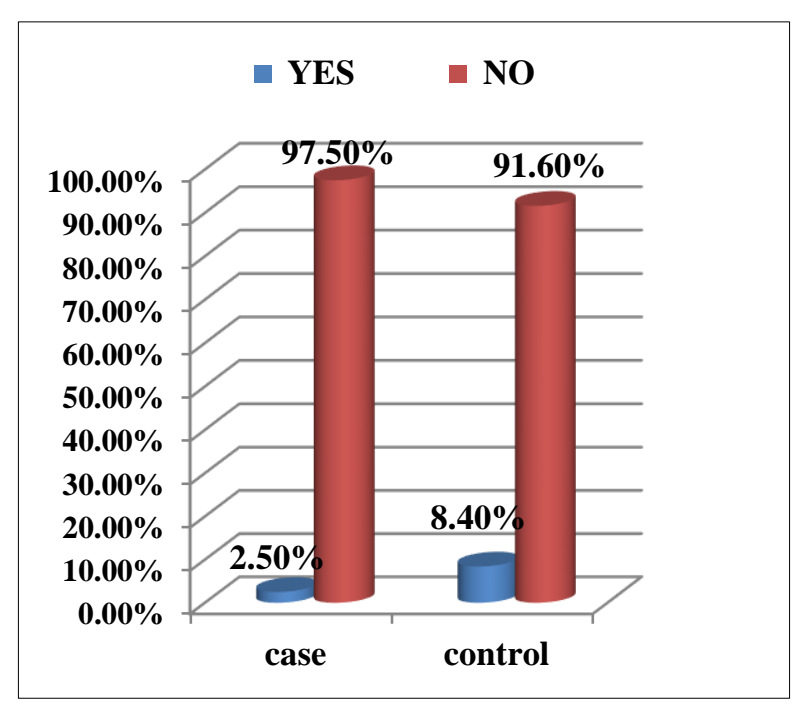

Figure 3: Postoperative headache among studied patients.

Postoperative headache was observed in both control $(8.4 \%)$ and intervention $(2.5 \%)$ groups $(\mathrm{P}=0.01)$ (Figure 3). Mean postoperative stay in intervention group $(30.08 \pm 9.50$ hours) was shorter than control group (50.1 \pm 6.4 hours) which was statistically significant $(\mathrm{p}=$ 0.01) (Figure 4).

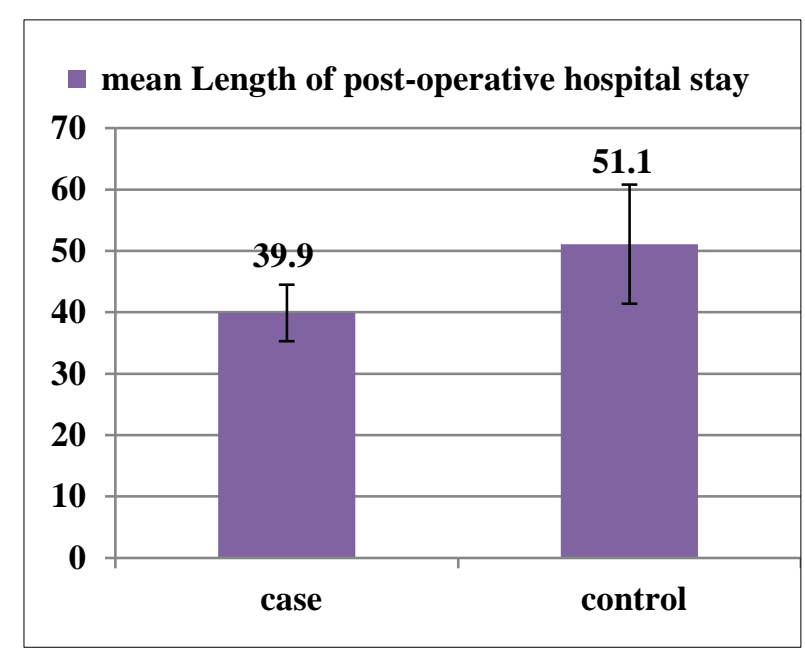

Figure 4: Length of post-operative hospital stay among studied patients.

\section{DISCUSSION}

CS is a common abdominal surgery showing an increasing trend over the last three decades. ${ }^{13}$ It is a lifesaving surgical procedure when certain complications arise during pregnancy and labor. However, it is a major surgery and is associated with immediate maternal and perinatal risks and may have implications for future 
pregnancies as well as long-term effects that are still being investigated. ${ }^{14}$

Many complications could occur after an abdominal surgery. So, after a caesarian section, complications that are variable in its intensity could occur. One of the commonest but yet serious is the postoperative ileus. ${ }^{1}$ Postoperative ileus complicates $10-15 \%$ of caesarian section deliveries. ${ }^{2}$ Postoperative ileus is a predictable delay in gastrointestinal motility that occurs after abdominal surgery. Probable causes include disruption of the sympathetic/parasympathetic pathways to the gastrointestinal tract, inflammatory changes through multiple pathways, and the use of opioids for the management of postoperative pain. ${ }^{15}$

Ileus is a major complication after caesarean section which is prompted by a number of factors including drug interactions, opioids and surgical procedures. As well as the large amount of blood and amniotic fluid shed in the peritoneal cavity during cesarean delivery with the measures that are done to clean up the peritoneal cavity with possible manipulation of the intestines increasing the possibility of ileus after it. ${ }^{16-17}$

Coffee is a popular global drink and positively affects human body including cardiovascular system and central nervous system, and improves one's sense of wellbeing. ${ }^{18}$ However, effects of coffee on gastrointestinal function are rarely studied in the literature. Cohn showed that consumption of coffee in young adults has positive effects on intestinal motility index and improves large intestine movements. ${ }^{19}$

The current study showed that there was no significant difference between groups regarding causes of caesarean section. In the intervention group there were 205 elective caesarean sections $(74.5 \%)$ and 70 emergent CS (25.4\%). In the control group there were 230 elective caesarean sections $(80.7 \%)$ and 55 emergent CS (19.3\%). This was the different to the findings of the study conducted by Rabiepoor et al, that only included women undergoing elective caesarean section only with no prior abdominal surgeries or previous caesarean sections. ${ }^{13}$ In the current study, mean operation duration among studied patients was $41.8 \pm 4.2$ in group $\mathrm{C}$ and $42.3 \pm 4.5$ in group $\mathrm{N}$ with no significant difference among groups. This observation was found to be in agreement with that reported by Rabiepoor et al. ${ }^{13}$

The present study shows that there were statistically significant differences between the two groups regarding the bowel function after CS except for the first time to defecation as there was a non-statistically significant difference between the two groups ( $p>0.05)$. As among the women of the intervention group the mean time for the first defecation was $29.1 \pm 2.9$ hours and it was $30.7 \pm 3.2$ hours in the women of the control group. Intestinal performance shows significant difference between two groups in passing the first flatus which was recorded at $14.9 \pm 2.1$ hours in the intervention group while it was $23.01 \pm 3.5$ hours in the control group which was statistically significant $(p=0.02)$. It also shows that first bowel sound was audible at $6.2 \pm 0.73$ hours and $9.9 \pm 1.2$ hours for intervention and control groups, respectively, which was statistically significant $(\mathrm{p}=$ $0.01)$.

This is in agreement with study conducted by Rabiepoor et al, who reported improved intestinal performance and shows significant difference between two groups in first flatus passage. ${ }^{13}$ But not coped with this study as it also showed that first bowel sound was recorded at $6.16 \pm 1.33$ hours and 5.84 \pm 1.41 hours for control and intervention groups, respectively, which was statistically insignificant $(\mathrm{p}=0.326)$. The first passage of flatus in intervention group (17.28 \pm 4.44 hours) occurred 5 hours earlier than control group (22.54 \pm 5.09 hours) and was statistically significant $(\mathrm{p}=0.0001)$, implying that coffee facilitates and accelerates passing first flatus.

First defecation was recorded at $37.22 \pm 16.31$ hours for intervention group and at $36.82 \pm 16.5$ hours for control group, showing no significant difference $(\mathrm{p}=0.647)$.

A similar study conducted by Dulskas et al, who studied the effect of coffee on the length of postoperative ileus after elective laparoscopic left-sided colectomy: a randomized, prospective single-center study, and reported that the time until the first bowel movement was significantly shorter in the decaffeinated coffee group $(3.00 \pm 1.50)(\mathrm{p}<0.05)$ versus coffee with caffeine $(3.75 \pm 1.53)$ versus the water group $(4.14 \pm 1.15) .{ }^{19}$ The time until the tolerance of solid food was significantly shorter in the decaffeinated group versus coffee with caffeine and the water group (1.85 versus 2.60 and 2.80; $\mathrm{p}<0.05)$. Time until the first flatus $(1.47$ versus 1.57 and 1.77 for decaffeinated coffee versus coffee with caffeine and water; $p>0.05$ ) did not show a significant difference. Postoperative hospital stay was similar in all 3 of the groups: 7.0 days in the water group, 6.6 in the decaffeinated coffee group, and 6.0 in the coffee group ( $p$ $=0.166$ ).

Similarly, Akhlaghi et al, examined effects of chewing gum on post-caesarean ileus and reported that first passage of flatus was faster for experimental group (14 hours) than control group (16 hours). ${ }^{20}$ The current study showed that there was no significant difference between groups regarding post-operative nausea and vomiting ( $\mathrm{p}>$ 0.05). Postoperative nausea and vomiting was observed in both control $(7.1 \%)$ and intervention $(10.9 \%)$ and there was significant difference between groups regarding Postoperative abdominal distension $(\mathrm{p}<0.05)$.

This is consistent with the study conducted by Rabiepoor et al, who reported postoperative nausea and vomiting was observed in both control $(8 \%)$ and intervention (10\%) groups but this difference was not statistically significant and was different with results of Amini et 
al. ${ }^{13,21}$ Who reported that nausea and vomiting were more frequent in early feeding group than control group, $40 \%$ versus $19 \%(p=0.012)$. This difference is probably due to differences in the type of intervention. This difference may be due to different surgical procedures applied in the two studies.

The present study showed that was significant difference between groups regarding postoperative headache. Postoperative headache was observed in both control $(8.4 \%)$ and intervention $(2.5 \%)$ groups $(P=0.01)$. Similar findings were reported by Masoudifar et al, who studied the effect of venous dexamethasone, oral caffeine and acetaminophen on relative frequency and intensity of post dural puncture headache after spinal anesthesia and showed that during the study, 24 patients in the control group and 17 patients in the intervention group were afflicted with headache; however, with no significant difference $(\mathrm{P}=0.14){ }^{22}$ Total frequency of headache incidence was 35 times in the control group and 27 times in the intervention group $(\mathrm{P}=0.32)$. Also, they reported that taking of acetaminophen + caffeine + dexamethasone is associated with a decrease in headache intensity and duration and decrease in PDPH incidence, compared with placebo, however, no statistically significant effect was produced.

Also, few studies and some case reports have recommended oral and intravenous caffeine as therapeutic option, although the recurrence of headache after caffeine treatment is frequent. ${ }^{23,24}$ However, no well-designed, adequately powered, randomized controlled trials have been conducted to prove the effectiveness of caffeine. Sechzer et al, study was carried out in 41 patients in whom intravenous administration of $500 \mathrm{mg}$ of caffeine sodium benzoate relieved $75 \%$ of headaches after lumbar puncture, with further improvement observed with a second dose..$^{23}$ Apparently, caffeine acts as a cerebral vasoconstrictor by blocking adenosine receptors, which has a role in the pathogenesis of headache after lumbar puncture.

Mean postoperative stay in intervention group (30.08 \pm 9.50 hours) was shorter than control group $(50.1 \pm 6.4$ hours $)$ which was statistically significant $(\mathrm{p}=$ $0.01)$. Furthermore, our results indicate that $10.9 \%$ of control group and $7.1 \%$ of intervention group experienced nausea, and relative risk of vomiting was 1.25 in both groups. However, this was not statistically significant $(\mathrm{p}=0.727)$.

This is inconsistent with the study conducted by Rabiepoor et al, who reported that the length of hospital stay for intervention and control groups was 30 and 32.16 hours, respectively, and showed no significant difference. ${ }^{13}$

Our results indicate that consuming coffee after CS contributes significantly to faster restoration of intestinal function. Coffee is a popular drink and can be used to decrease postoperative ileus-related complications. The study faced some limitations as there was no similar study on effects of coffee on post elective and emergent caesarean section paralytic ileus. Also, the relatively small number of patients, drop out of patient and duration of treatment is to some extend short duration and indeed a randomized trial is warranted before the final conclusion.

It is suggested that further studies apply different protocols with different timing and longer coffee treatment, like giving coffee perhaps before caesarean section, to see its effects on postoperative gastrointestinal function and post-operative headache. It is also suggested to incorporate the effect of coffee on the need for analgesia in the next studies.

\section{CONCLUSION}

In conclusion, consuming coffee after CS contributes significantly to faster restoration of intestinal function. Coffee is a popular drink and can be used to decrease the incidence of postoperative ileus-related complications and it is also related to reduction in post CS spinal headache as a secondary objective.

\section{ACKNOWLEDGMENTS}

Authors would like to express their gratitude to the patients who participated in this study and to the colleagues and nurses at the Ain Shams University Maternity Hospital, Cairo, Egypt.

\section{Funding: No funding sources}

Conflict of interest: None declared

Ethical approval: The study was approved by the Institutional Ethics Committee

\section{REFERENCES}

1. Sunil S, Sinha S. Postoperative ileus: a preventable event. Br J Surg. 2000;87:1480-93.

2. Teoh WH, Shah MK, Mah CL. A randomised controlled trial on beneficial effects of early feeding post-Caesarean delivery under regional anaesthesia. Singapore Med J. 2007;48(2):152.

3. Holte K, Kehlet H. Postoperative ileus: progress towards effective management. Drugs. 2002;62(18):2603-15.

4. Toyomasu Y, Mochiki E, Morita H, Ogawa A, Yanai M, Ohno T, et al. Mosapride citrate improves postoperative ileus of patients with colectomy. J Gastroint Surg. 2011;15(8):1361-7.

5. Drake TM, Ward AE. Pharmacological management to prevent ileus in major abdominal surgery: a systematic review and meta-analysis. J Gastroint Surg. 2016;20(6):1253-64.

6. Tan EK, Cornish J, Darzi AW, Tekkis PP. Metaanalysis: alvimopan vs. placebo in the treatment of post-operative ileus. Alim Pharmacol Therap. 2007;25(1):47-57. 
7. Beck DE, Sweeney WB, McCarter MD, Ipamorelin 201 Study Group. Prospective, randomized, controlled, proof-of-concept study of the Ghrelin mimetic ipamorelin for the management of postoperative ileus in bowel resection patients. Int $\mathrm{J}$ Colorectal Dis. 2014;29(12):1527-34.

8. Zhuang CL, Ye XZ, Zhang CJ, Dong QT, Chen BC, $\mathrm{Yu}$ Z. Early versus traditional postoperative oral feeding in patients undergoing elective colorectal surgery: a meta-analysis of randomized clinical trials. Digest Surg. 2013;30(3):225-32.

9. Ertas IE, Gungorduk K. Influence of gum chewing on postoperative bowel activity after complete staging surgery for gynecological malignancies: a randomized controlled trial. Gynecol Oncol. 2013;131(1):118-22.

10. Bragg D, El-Sharkawy AM. Postoperative ileus: Recent developments in pathophysiology and management. Clin Nutr. 2015;34:367-76.

11. Brown SR, Cann PA, Read NW. Effect of coffee on distal colon function. Gut. 1990;31(4):450-3.

12. Müller S, Rahbari N, Schneider F, Warschkow R, Simon T, von Frankenberg M. Randomized clinical trial on the effect of coffee on postoperative ileus following elective colectomy. $\mathrm{Br} \quad \mathrm{J}$ Surg. 2012;99(11):1530-8.

13. Rabiepoor S, Yas A, Navaei J, Khalkhali HR. Does coffee affect the bowel function after caesarean section?. Eur J Obstet Gynecol Repro Biol. 2018;220:96-9.

14. Gregory KD, Jackson S, Korst L, Fridman M. Cesarean versus vaginal delivery: whose risks? Whose benefits? Am J Perinatol. 2012;29(1):7-18.

15. Ratnalikar V, Williams C, Moses T. Perioperative pain management in colorectal surgery. Surg (Oxford). 2017;35(8):426-31.

16. Sarwar I, Haider S, Khan AB. Effect of early and delayed oral feeding on early ambulation of patients after cesarean section: a randomized controlled trial. J Rehman Med Instit. 2018;2(3).

17. Gómez-Izquierdo JC, Trainito A, Mirzakandov D, Stein BL, Liberman S, Charlebois P, et al. Goal- directed fluid therapy does not reduce primary postoperative ileus after elective laparoscopic colorectal surgery. A randomized controlled trial. anesthesiology: J Am Soc Anesthesiol. 2017;127(1):36-49.

18. Zucconi S, Volpato C, Adinolfi F, Gandini E, Gentile E, Loi A, et al. Gathering consumption data on specific consumer groups of energy drinks. EFSA 2013;10:394E.

19. Dulskas A, Klimovskij M, Vitkauskiene M, Samalavicius NE. Effect of coffee on the length of postoperative ileus after elective laparoscopic left-sided colectomy: a randomized, prospective single-center study. Dis Colon Rectum. 2015;58(11):1064-9.

20. Akhlaghi F, Pourjavad M, Mansouri A, Tara F, Vahedian M. Effect of gum chewing on prevention of post cesarean ileus. J Hayat. 2008;14(2):35-40.

21. Amini A, Mortazavi A, Nojoomi M. Assessment of early oral feeding on gastrointestinal symptoms after cesarean delivery and total abdominal hysterectomy. Razi J Med Sci. 2005;11(44):895-900.

22. Masoudifar M, Aghadavoudi O, Adib S. Effect of venous dexamethasone, oral caffeine and acetaminophen on relative frequency and intensity of postdural puncture headache after spinal anesthesia. Adv Biomed Res. 2016:5

23. Sechzer PH, Abel L. Post-spinal anaesthesia headache treated with caffeine. PartII. Curr Ther Res. 1979;26:440-8.

24. Sandesc D, Lupei MI, Sirbu C. Conventional treatment or epidural blood patch for the treatment of different etiologies of post dural puncture headache. Acta Anaesthesiol Belg. 2005;56:265-9.

Cite this article as: Nadim AA, Ghanem RM, Benyamine MG, Abdallah FN, Abbas AM. The effect of caffeine ingestion in prevention of postoperative ileus after caesarean section: a randomized controlled trial. Int J Reprod Contracept Obstet Gynecol 2019;8:4808-14. 